\title{
Entrepreneurship in Social-Media Services in Oman - A Socio-Economic Scanning of the Sultanate
}

\author{
Baby Sam Samuel ${ }^{1} \&$ Prof. Joe Sarprasatha ${ }^{2}$ \\ ${ }^{1}$ Research Scholar, SRM University, Chennai, India \\ 2 Professor, SRM School of Management, SRM University Chennai, India \\ Correspondence: Baby Sam Samuel, Research Scholar, SRM School of Management, SRM University, SRM \\ Nagar, Potheri, Kattankulathur-603203, Kancheepuram, Tamil Nadu, India. Tel: 91-906-188-1111. E-mail: \\ s.babysam@gmail.com
}

Received: February 2, 2016 Accepted: March 10, 2016 Online Published: March 18, 2016

doi:10.5539/ass.v12n4p138

URL: http://dx.doi.org/10.5539/ass.v12n4p138

\begin{abstract}
The document explores the background of entrepreneurship and social media from the perspective of the Sultanate of Oman, and explores the prevalence and usage of social media and social media business services across the Arab world and in particular, Oman. The review of data and of available literature reveals that entrepreneurship is increasingly being promoted in Oman as part of a strategy to promote the diversification of economy in light of declining oil prices and depleting oil reserves.

With a view of exploring the scope of social media related services as a means of entrepreneurial ventures, the potential benefits of social media for businesses, the possible opportunities and challenges in entrepreneurship in social media management and marketing services in Oman have been reviewed and highlighted. The review reveals that in Oman and across the Arab region, as social media usage by businesses is gaining prominence, the lack of digital skills could act as a promoter for outsourcing of social media to external social media service agencies. The studies also reveal the gap between client expectations and the currently available services. In this light, the study concludes that this is a viable area for research that merits further exploration.
\end{abstract}

Keywords: entrepreneurship, social media, social media marketing, social media agency, Sultanate of Oman

\section{Introduction}

Social media and social networking sites have become ubiquitous and have brought in a multitude of ways for a business to connect with its potential and intended consumers. This study explores the background of entrepreneurship and social media services from the perspective of the Sultanate of Oman. In Oman as in the Middle East, social media is steadily gaining user base and this could translate as opportunities for businesses to harness the power of social media to create and enhance consumer engagement which could in turn mean scope for social media services as a business in itself.

The present research attempts to review the literature across three topics. The first topic looks at the usage of social media across Oman and the Arab region. The second highlights the usage of social media by businesses in the region while the third topic explores the scope of social media services as a platform for businesses in Oman and discusses the factors influencing entrepreneurship within the nation. The secondary sources include books, research articles, research reports, online articles and other statistical data, obtained through a thorough search of the databases.

What makes the research pertinent is the economic and cultural background of Oman. Sultanate of Oman, also called Oman, is an Arab monarchy located in the southwest Asia, between Yemen and UAE. The nation is heavily dependent on oil, the reserves of which are fast depleting. The future of its economy is entirely dependent on its successful diversification. Adding to that the current decline in crude oil prices have further increased the need for and focus on entrepreneurship.

For a country like Oman where exists media and cultural restrictions that prevent or inhibit open exchange of thoughts and ideas and where Arabic is the predominant language, social media has managed to gain a foothold among the population. Social Media as a disruptor of the established norms and practices could be the threshold to a new era for the Oman population and economy. 


\section{Social Media Usage across Oman}

\subsection{Social Media Definition}

Andreas Kaplan and Michael Haenlein defined social Media as a group of Internet-based applications that build on the ideological and technological foundations of Web 2.0, and that allow the creation and exchange of User Generated Content (Kaplan \& Haenlein, 2010). It can be considered as a "social phenomenon" (Toral, Martinez-Torres, Barrero, \& Cortes, 2009) and as "social spaces" (Nambisan \& Watt, 2011).

Social media involves the use of web-based technologies for the purpose of social interaction. It encompasses all activities that include a social aspect and is therefore extensive.

\subsection{Usage of Popular Social Media Platforms}

Arab Media Outlook 2008-2012 reported in 2009 that digital media would flourish in the Arab region because of this market's technologically inclined, young demographic group (AMO, 2009). In the GCC countries, one-third to half of the population is younger than 25 years while in Oman, half of the population is under the age of 25 (Booz \& Co, 2011).

And as predicted, there has been consistently strong growth in social media usage across the Arab region (Salem, Mourtada, \& Alshaer, 2014; Arab Social Media report, 2015). However, the social media penetration in Oman is still behind other GCC countries (Mediate, 2015).

Some of the currently popular social media are as follows:

- Facebook - Largest online social networking site

- Twitter - Micro blogging service

- $\quad$ LinkedIn -Professional network

- YouTube - Video Sharing website

- Instagram - Photo \& Video sharing service

- $\quad$ Google Plus - Social Networking site by Google

Globally, Facebook is the frontrunner in social networks, with 1.23 billion active users worldwide (Facebook, 2015; Duggan, Ellison, Lampe, Lenhart, \& Madden, 2015) while in the Arab world too Facebook is the top used social media platform (Markaz, 2014; Arab Social Media report, 2015). The total number of Facebook users in the Arab region increased by 26749189 from 2013 to 2014 while the average Facebook penetration of the countries in the Arab region increased to $21.5 \%$ from $15 \%$ in the same period. (Salem et al., 2014). Facebook penetration in Oman which was $18.9 \%$ in 2012 increased to $27.9 \%$ in 2014. The number of Facebook subscribers in Oman crossed 800,000 as of May 2014 with 264,480 new users between Jan to May 2014 (Salem et al., 2014).

Twitter reached the 500 million mark in February 2012 and currently, there are 302 million monthly active users, with 500 million Tweets being sent per day across the globe (Twitter, 2015). The Dubai School of Government reported in 2013 that the number of Twitter users in the region had increased by over 79\% (Salem, Mourtada, \& Alshaer, 2013). In a research that studied the usage of Twitter in each of the 22 Arab nations, it was observed that the total number of active Twitter users in the Arab world had crossed 5797500 users in March 2014 with an average of 17198900 tweets per day estimated to be produced from the Arab region (Salem et al., 2014). In the Sultanate, the number of active users of Twitter had increased from 14000 in 2012 to 38000 in 2013. The total number of accounts also increased from around 200000 in 2012 to 300000 in 2013 (Arab Social Media report, 2015).

LinkedIn has more than 313 million members in over 200 countries and territories. (LinkedIn, 2015). According to Arab Youth Survey users from Middle East and North Africa account for over 14 million in 2015 which was up increasing from 5 million in 2012 (Arab Youth Survey, 2015). In 2012, the Sultanate had 115,761 members on LinkedIn of which 89\% were aged between 18 and 34 (GWI, 2015).

More than 1 billion unique users across the world visit YouTube each month while over 6 billion hours of video are watched each month on YouTube and 100 hours of video are uploaded to YouTube every minute (YouTube, 2015). In the MENA region, 280 million YouTube videos are viewed every day and two hours of content is uploaded every single minute, according to Discover Digital Arabia (Arab Youth Survey, 2015). According to the 2015 Arab Social Media report, 40\% of social media users in Oman are users of YouTube among whom 57\% access YouTube on a daily basis (Arab Social Media report, 2015).

Instagram, a social networking service with focus on sharing photographs and videos, was one of the fastest 
growing networks in the world in 2013 with 150 million users and 40 million photos being uploaded each day. In 2014, Instagram had surpassed 200 million monthly active users. (Instagram, 2015). In the Arab world, almost one third (34\%) of social media users have current subscription in Instagram while 4 out of 5 users of social media in the region access Instagram on daily basis. (Arab Social Media Report, 2015). In Oman, $40 \%$ of social media users are users of Instagram. Daily access to Instagram was seen in $86 \%$ of these users, of which $37 \%$ access it via the smartphone app (Arab Social Media report, 2015).

The promulgation of social media in the Arab world has led to the growth of Arabic on the various platforms and the introduction of Arabic platforms have inversely aided in the increased usage of social media in the region. Arabic is the fastest emerging language on Facebook while Twitter, LinkedIn and others too have introduced Arabic language (Arab Youth Survey, 2015). Salem and Mourtada (2012) found that Arabic is the preferred language of Facebook users in several Arab countries but English was preferred by majorities in Oman.

\section{Social Media by Businesses}

The digital media has revolutionized the world and has altered consumer behavior; social media and internet has empowered digital savvy consumers to make informed choices. In response, businesses too are evolving and social media is gaining prominence in their marketing strategies. The reach and visibility of business on social media has been much written about globally. (Y\&R, 2015; McKinsey \& Co, 2012; Balan, 2014; World Economic Forum (WEF), 2015 etc.) The 2014 Social Media Marketing Industry Report stated that more than 90\% of marketers declared that social media was important for their business, as compared to the $86 \%$ in 2013 (Stelzner, 2014). Social media marketing as a marketing tool has also come to be economic and beneficial for SMEs who do not have a high marketing budget (McKinsey \& Co, 2012; Saleh, 2012). Globally, Facebook heads the social marketing sphere with 1 million active advertisers (Facebook, 2015).

\subsection{Benefits of Social Media for Businesses}

Stefanie Ellen Dierdorp, (2013) in her paper on A Framework for a Social Media Dashboard for Entrepreneurs lists out the following opportunities for Entrepreneurs provided by Social Media whereby it acts as an important, if not essential part of business strategy (Dierdorp, 2013):

\subsubsection{Idea Generation}

Customers can become involved in the process of collecting the service requirements, understanding the needs and problems; identifying potential solutions; and evaluation of existing services. Companies can also reach potential customers with the help of online communities whereby these clients can provide relevant user feedback through various means.

\subsubsection{Idea Refinement}

Customers can aid in reviewing and fine-tuning ideas. They can suggest improvements and additional features; provide feedback on concepts through rating systems; questionnaires etc.

\subsubsection{System Design}

Customers can be engaged in online discussions and multimedia content evaluation whereby they can suggest improvements, identify pluses and minuses in system design.

\subsubsection{Service Testing and Pilot Run}

Customers can be a part of pilot testing groups and can be enrolled through a company's or a business's social media pages. The potential clients can thus participate in the review of service concepts; testing of products and services and suggest improvements.

\subsubsection{Test Marketing}

Customer inputs on marketing plan can be collected through social media. Their levels of satisfaction on marketing can be gauged along with gathering suggestions for improvement.

Regional brands across the Arab world have begun to realize the potential of digital and social media and are increasingly utilizing social media as part of their digital marketing campaigns to increase their reach and visibility across local and global audiences. In a regional survey, Arab Media Outlook reported that majority of the surveyed companies (88\%) planned to utilize social media in some form or the other while $19 \%$ of the companies surveyed were seen to be intensely involved in social media (AMO, 2012).

In 2015, the Arab Social Media Report, 2015 studied the usage of social media across the Arab region and observed that businesses across the entire region have utilize social media mainly for its use as a marketing tool and to drive sales and growth (Arab Social Media Report, 2015). 
Oman has made certain extent of progress in terms of digitalization of governance. Al-Badi (2014) studied the usage of social media among the government agencies of GCC. The study revealed that almost half of the studied ministries $(46 \%)$ in Oman were adopters of social media. Growing on the global trend, social media has begun to be adopted by the public at large in Oman and Brands too. Businesses in Oman have begun to embrace social media as ways and means to reach Omani as well as global audience and to facilitate multi-way dialogues with their customers.

According to Mediate (2015), most of the companies in Oman are transitioning from a stage where they were hesitant to use social media to a learning stage where they are experimenting on social media either on their own or through agencies. An example of a business incorporating social media into its strategy is TOTEM, a retail shop in Oman and is one of the first few shops to directly sell their wares online through social media (OCI, 2015). According to Social Bakers (2015), the top 5 brands on Facebook in Oman, in terms of the total number of fans are as follows:

Table 1. The top 5 brands on Facebook in Oman

\begin{tabular}{ccc}
\hline Top Brands & Local Fans & Total fans \\
\hline Oman Air & 97986 & 896618 \\
Ooredoo Oman & 120544 & 185551 \\
Oman Air Arabic & 9472 & 142459 \\
City Centre & 47988 & 101917 \\
Omantel & 72233 & 98858 \\
\hline
\end{tabular}

The top twitter profiles, in terms of the number of followers are as follows: (Social Bakers, 2015)

Table 2. The top 5 brands on Twitter in Oman

\begin{tabular}{cc}
\hline Top Brand Profiles & Followers \\
\hline Omantel & 102294 \\
Ooredoo Oman & 96069 \\
Oman Air & 78451 \\
Bank Muscat & 41777 \\
Sohar & 28695 \\
\hline
\end{tabular}

Similarly, the top YouTube accounts are as follows, in terms of the number of views obtained for the account: (Social Bakers, 2015)

Table 3. The top 5 brands on YouTube in Oman

\begin{tabular}{ccc}
\hline Top Brands & No of Subscribers & No of views \\
\hline Nawras 1500 & 628 & 391971 \\
Toyota Oman & 236 & 191618 \\
Bank Muscat & 166 & 158303 \\
Omran SAOC & 242 & 56169 \\
Kia Oman & 83 & 12947 \\
\hline
\end{tabular}

The Oman Information Technology Authority has supported the view that usage of social media as a communication channel can reflect the preferences of Omanis. (ITA, 2013) However, the Arab Social Media Report, 2015 posits that the Arab region has a long way to go before social media can completely relied on to drive sales.

\section{Scope of Social Media Services as a Platform for Businesses in Oman}

The level of digital skills within an organisation is an important parameter affecting the social media usage. One of the reasons companies outsource their social media to agencies is to avail the skills of the external agencies which is oftentimes lacking within the organization (Balan, 2014). The digital marketing report by SoDA observed that creating digital experiences was not among the core capabilities of large organizations. (The SoDA 
Report, 2014). The lack of digital skills has been highlighted globally as one of the barriers in implementation of social media by businesses. (Capgemini Consulting, 2011; SMMITS, 2015) A Digital Maturity Assessment survey highlighted that over $50 \%$ of companies studied lacked social media skills while they reported that over $90 \%$ of the companies studied did not have the requisite skills in the areas of social media and networks, and also in the monitoring and analyses of their performance (Spitzer et al., 2013). While Capgemini's research with the MIT in 2011 uncovered that majority (87\%) of the studied companies felt that digital transformation was a competitive opportunity (Capgemini Consulting, 2011); however, their study in 2012 showed that only $46 \%$ of companies were spending on the enhancement of their digital related skills (Spitzer et al., 2013). In the Arab region, the lack of skills in this region was particularly stated as a drawback for businesses by Dubai School of Government's study on Social Media, Employment and Entrepreneurship (2012) and emphasized that there existed a deficit in the social media related capabilities and skills in the region to support the businesses utilizing social media. This was further underlined in the case of Oman by the Mediate study which reported that among the obstacles for creating quality content were cited lack of resources (33.9\%), insufficient agency expertise (26.8\%) and insufficient in-house expertise (26.8\%) (Mediate, 2015).

Hall (2013) listed the various capabilities that would be required by businesses from these external vendors which includes the digital and technical skills related to social media monitoring, analyses of the social media conversations, marketing and sales, customer profiling, knowledge transfer etc. and also the capability of offering skilled human resources.

These external vendors are usually online marketing companies, digital media agencies, creative agencies etc. and the social media services they offer could comprise any or all of the following:

- Social Media Strategy Planning \& Development

Development of comprehensive social strategies that are based on client's needs, to make their social media platforms into successful brands. This includes audience and Influencer identification and strategies for activation and outreach.

- $\quad$ Marketing through social media platforms

Involves marketing through different types of popular social media like Facebook, Twitter, Google +, Linked In, YouTube, Pinterest, Instagram etc.

- Ad management on social media

Management of advertisements in the form of banners, display ads and other ads on social media platforms.

- $\quad$ Social Media Consulting

Social media consultant offers consultancy services in determining where the opportunities in social media are, specific for each client.

- Social Media Competitions \& campaigns

Development of highly-targeted social campaigns and competitions to build interaction, grow and engage fans and enhance online presence.

- Social Media Applications

Development of applications that work within various social media, in order to further enhance the interaction of customers with a company's brand and products

- Social copywriting and content development

Creation of copy and other content specifically for social media promotions

- $\quad$ Social Media Monitoring

Monitoring of the social media sphere to discover and analyze what is being said about the client

- Social ecosystem and competitive analysis

Performance of in-depth analyses of the social media content and also identify the tactics and create action alerts for current and potential competitors.

- Measurement \& Analytics

Analyses of the effectiveness of the various strategies, campaigns and social media presence

According to the 2014 social media marketing industry report by Social Media Examiner, Design/ Development, Content creation, Analytics, Monitoring, Research, Status updates, Strategy, Community Management are some 
of the areas of social media that are outsourced to external agencies which are more or less similar for B2C or B2B businesses (Stelzner, 2014; B2B, 2014). Core Media 2015 Outlook studied the media industry in Ireland and concluded that there is a positive shift towards media agencies that can offer cohesive mix of media and creative services and consequently agencies have started to invest in resources skilled in digital activities (Cox, 2015). Arab Media Outlook too supports the view that as companies are still in a developing phase when it comes to their experimentation with social media, the digital agencies could aid smaller companies in making full use of the potential offered by digital media (AMO, 2012).

A major reason for outsourcing social media is the lack of time as cited in many studies in the developed world. CBI (2014) reports that many companies opt for outsourcing their social media to external service providers since the various aspects of social media like content management, its analyses and monitoring are tedious processes that are time consuming.

Catering to the businesses in Oman are a few entrepreneurial ventures delving in social media services as per Oman's media directory Mediate, which lists the agencies offering social media services. Most of these companies are digital agencies whose core offerings are web development, digital media, advertising etc. (Mediate, 2015).

However, Recma report suggests that large multinational brands having presence in Oman utilize pan Arabian digital media agencies for their advertisement and media activities (Recma, 2015). In an argument on utilizing onshore service providers as against offshore service providers, Hall (2013) summarizes that onshore service providers, i.e. providers within the same country (CBI, 2014) are generally better suited to provide services across more service lines than offshore providers, thereby making a case in point for social media agencies within Oman. Moreover, Hall (2013) observes that onshore service model could remain dominant over offshore services as agencies within the nation are better able to understand the brands and the closer proximity enables better interaction with the clients.

Arab Media Outlook pointed out a gap between the advertising spend per capita in the Arab region as compared to the global values and noted that this gap could signify potential for growth in the advertising spend in this region (AMO, 2012). In Oman, the spending on digital advertising was only 3\% of the total ad spend in 2012 and was estimated to be less than 1 million USD (AMO, 2012) and observed that digital media agencies themselves could act as a catalyst for the growth of spending on digital advertising.

The disparity could be because of a gap in the services rendered and the client's requirements. This is further brought to light in Mediate (2015) which reported that that there seemed to be disconnect between client expectations and what the media and agencies are delivering in Oman, indicating a potential for bettering the services and meeting the demand.

The lack of local language digital content in the MENA region despite the increasing usage of social media in this region have been reported in studies (GSMA, 2014; Abu Dhabi Media Summit, 2014), and is an issue that could be mitigated through localized social media agencies that can provide local and relevant content in Arabic too.

\subsection{Need for Entrepreneurship in Oman}

On the strength of the oil capital and the developments made since the current ruler Sultan Qaboos bin Said began control of the nation in 1970, Oman is considered as one of the most progressive nations in the Middle East. However, Oman is only a modest producer with depleting oil reserves and has therefore been focusing on diversification of its economy through various government measures (BTI, 2014; Central Intelligence Agency, 2013). The Small and Medium Enterprises (SME) sector in Oman is in its nascent stages and the contribution of SMEs to GDP was 16 percent in 2012 (Central Bank of Oman, 2014). The recent decline in prices of crude oil has further increased the urgency to minimize the dependence on oil while adding new economic sectors to the domestic economy (SME Advisor, 2016). There is therefore renewed focus on enhancing and encouraging entrepreneurship.

Entrepreneurs are often found to have a major role to play in the economic and social growth of nations (Ozbilgin, 2009). There are various ways in which entrepreneurship may affect economic growth. Its impact on a nation's growth is reflected in the definition by European Commission which describes it as "the mindset and process to create and develop economic activity by blending risk-taking, creativity and/or innovation with sound management, within a new or an existing organization" (European Commission, 2003). It is through the efforts of entrepreneurs that important breakthroughs, innovative products, solutions or business processes are often introduced into markets (Acs \& Audretsch, 1990 \& 2003). Entrepreneurship is thus vital for larger economy 
(Shrivastava \& Shrivastava, 2013).

\subsection{Factors Promoting Entrepreneurship in Oman}

\subsubsection{Governmental Policies}

Vision 2020 is a long term diversification plan for Oman's economy, in line with the instruction of the country's ruler, His Majesty Sultan Qaboos bin Said, that outlines the country's economic and social goals to be achieved by 2020, through four major strategies: Sustainable Development within a Stable Macroeconomic framework, Human Resources Development, Diversification of Economy, and Development of the Private Sector (The research council, 2013)

Accordingly, the Sultanate government has undertaken various strategies that increase and promote the participation of the Omani private sector in the nation's development. A number of governmental strategies such as the privatization policy, SAS Program, Sharakah and non-governmental initiatives such as Intilaaqah, etc. were implemented to encourage the participation of the private sector (ITA, 2013; Ashrafi \& Murtaza, 2008; Shachmurove, 2009; UNICEF Oman, 2010).

\subsubsection{Business Readiness}

Oman as a nation was ranked $12^{\text {th }}$ for Government Efficiency, according to the World Economic Forum (WEF, 2015). As per reports by National Center for statistics and Information, in 2014, the Sultanate ranked $31^{\text {st }}$ at World Level on Enabling World Trade Index (2014) while it ranked third position at both Arab and GCC States levels (NCSI, 2015). The World Bank's ease of doing business index ranked Oman $47^{\text {th }}$ in 2014 , up from the $65^{\text {th }}$ rank in 2010. These rankings reflect the nation's competitive business environment (Doing Business 2014 \& 2010).

\subsubsection{Technological readiness in Oman}

According to Facebook (2015), of the 1.23 billion active users, 945 million access the Facebook platform through their mobiles. Therefore, the penetration of mobile and other internet enabled devices could mean an increase in social media usage. According to research by We are social, the mobile subscription penetration in Oman had crossed $174 \%$ in 2014 against a global average of 98\% (We are social, 2014).

As per 2014 Global Competitiveness Report, Oman ranked 57 in technological readiness (WEF, 2015). The percentage of internet users in Oman has increased exponentially in the last fifteen years from $3.5 \%$ in 2000 to $70.2 \%$ of the total population in 2014 , largely due to devices like smartphones, tablets, and laptops that are mobile and internet enabled (Worldbank, 2015). A survey by ITA, Oman reported in 2014 that as many as $80 \%$ of households in Oman have access to internet (ITA, 2014). There were 195549 internet subscribers by May 2015, as per National Center for statistics and Information (NCSI, 2015). Oman offers high speed internet. According to Mediate, the relatively high usage of YouTube in Oman could be an indication of this access to bandwidth (Mediate, 2015).

\subsection{Hurdles \& Challenges}

Although many positive steps are being taken by government to facilitate the growth of entrepreneurship and SMEs, a lot remains to be desired. Some of the challenges faced by the entrepreneurs and social media marketers are as follows:

\subsubsection{Lack of Innovation}

According to the Global Competitiveness Report, Oman ranked 44 in innovation and sophistication factors (WEF 2015). However, Dhafir Awadh Al-Shanfari (2012) reported that amendments in Oman's entrepreneurship policy objectives are required in order for the entrepreneurial environment to be more innovation based rather than being merely copycat ventures of low potential. (Al-Shanfari, 2012).

\subsubsection{Financial Infrastructure}

Research has observed that one of the challenges faced by Oman Entrepreneurs was the lack of diversity in seed capital financing sources (Al-Shanfari, 2012).

\subsubsection{Regulatory \& Administrative Environment}

The 2012 study by the Dubai School of Government emphasized that most nations in the Arab region were devoid of dedicated policies or regulatory framework for social media-related content. This in turn has led to ambiguity and confusion and acts as a deterrent for fully exploiting the potential offered by social media (Dubai School of Government (2012). In an Arabian Research Bureau survey on enabling environment for sustainable enterprises assessment, 70 percent of surveyed firms believe that Oman's regulatory environment makes it 
difficult for small businesses to compete with large businesses (Buckley \& Rynhart, 2011). Moreover, businesses find lack of clarity in governmental policies, especially those related to manpower, Omanisation and labor regulations (OER, 2012).

\subsubsection{Organizational Culture \& Regional Attitudes}

According to the 2011 E-consultancy report, some of the biggest barriers that deter or limit a firm's digital marketing spending include the firm's culture, its reliance on traditional marketing and the ignorance of digital (E-consultancy, 2011). On a regional note, some social media users in the region display mistrust in social media and believe that it could adversely affect their culture and traditions (Arab Social Media Report, 2015) while students are also concerned about its disruptive effects of information overload. (Al-Harrasi \& Al-Badi, 2014) As internet penetration increases, although there is increased press freedom recently (AMO, 2012) a point of concern is the control and censorship exerted by government on the media in Oman (BTI, 2014).

\section{Conclusion}

The look at the social media scene across the Arab world reveals that following the global outbreak of social media social media is increasingly gaining usage across the Arab region although there are cultural restrictions and inhibitions. This is also true of Oman where technological readiness and smartphone penetration has aided in the propagation of social media. The increasing acceptance of social media among its people has heralded a change in the way businesses engage with them on social media with many businesses across the region and in Oman taking up social media to engage with their local and global audience. However, the lack of digital media skills in the region, particularly within the nation Oman has hindered local businesses from fully exploiting the potential of this new age media.

This presents opportunities in entrepreneurship for digital and social media agencies who understand the needs of the businesses and brands and can offer social media related services like social media management and make available local, relevant content in multiple languages to meet the changing needs of businesses in the Sultanate. The list of social media related services listed in this study is only indicative of the globally popular services rendered; there is no limit to the creativity and initiatives for social media agencies as the scope of social media related services is so vast both in its diversity and quantity.

Additionally, although there are some hurdles to be overcome, the socio-politic environment in the Sultanate seems to support entrepreneurial ventures and the explosion of digital media combined with the support for entrepreneurial growth in the nation indicates a favorable scenario for the social media entrepreneurs.

The review recommends further research into the following areas:

1. An in-depth study into the social media aspirations, perceptions, usage pattern and behavior of the various demographics that comprise Oman as apart from pan Arabian studies, there are no studies dedicated to Oman that studies the behavior, pattern and motivations of the general demographics in Oman which could add supplemental insight for marketers.

2. An in-depth study of the businesses in Oman pertaining to their need for social media services from external agencies and exploring further the current gap in the services rendered and their expectations. Although social media and related services has been extensively studied and written about globally, in the context of a developing nation like Oman, its scope for entrepreneurship, opportunities and challenges of this field, future potential remain as yet unexplored.

Therefore, this study concluded that an in-depth look at the scope of entrepreneurship in the field of social media services in the context of the Sultanate of Oman is viable and can help outline the prospects and challenges faced by entrepreneurs delving in social media services. At a time when there is increasing focus on promoting entrepreneurship thereby diversifying the nation's economy, further research in this area seems all the more relevant.

\section{References}

Abu Dhabi Media Summit. (2014). How Young Arabs are Fuelling the MENA Media Market. Arab Media Perspectives (1st ed.).

Acs, Z. J., \& Audretsch, D. B. (1990). Innovation and Small Firms. Cambridge, MA: MIT Press.

Acs, Z. J., \& Audretsch, D. B. (2003). Innovation and technological change. In Z. J. Acs, \& D. B. Audretsch (Eds.), Handbook of Entrepreneurship Research (pp. 55-79). Boston: Kluwer Academic Publishers

Al-Badi, A. H. (2014). The adoption of social media in government agencies: Gulf Cooperation Council case 
study. Journal of Technology Research, 5, 1-26.

Al-Harrasi, A. S., \& Al-Badi, A. H. (2014). The Impact of Social Networking: A study of the influence of smartphones on college students. Contemporary Issues in Education Research, 7(2).

Al-Shanfari, D. A. (2012). Entrepreneurship in Oman: A Snapshot of the Main Challenges, Multi-Year Expert Meeting on Enterprise Development Policies and Capacity-building in Science. Technology and Innovation (Fourth session) Geneva, 16-18 January 2012

AMO. (2009). The Arab Media Outlook, 2008-2012. Dubai Press Club and Pricewaterhouse Coopers.

AMO. (2012). Arab Media: Exposure \& Transition. Arab Media Outlook, 2011-2015 (4th ed.). Dubai Press Club.

Arab Social Media Report. (2015). Arab Social Media Report 2015. Arab Social Media Influencer's Summit.

Arab Youth Survey. (2015). 7th Annual ASDA'A Burson- Marsteller Arab Youth Survey. White Paper on "With the legacy of the Arab Spring waning, Arab youth are uncertain whether democracy could ever work in the Middle East." 2015.

Ashrafi, R., \& Murtaza, M. (2008). Use and Impact of ICT on SMEs in Oman. Electronic Journal of Information Systems Evaluation, 11(3).

B2B. (2014). B2B Benchmarks, Budgets, and 2014 Trends-North America. Content Marketing Institute, Marketing Profs

Balan, C. (2014). Consumer behaviour in the digital era - evidence from Romanian market. Journal of Economics and Management, 15.

Booz \& Co. (2011). Dr. Mona Al Munajjed \& Dr. Karim Sabbagh Youth in GCC Countries.Meeting the Challenge. Ideation Center Insight, Sept. 2011.

BTI. (2014). Bertelsmann Stiftung, BTI 2014 - Oman Country Report. Gütersloh: Bertelsmann Stiftung.

Buckley, G., \& Rynhart, G. (2011). The Sultanate of Oman The enabling environment for sustainable enterprises: An "EESE” Assessment. Employment Sector Employment Report, No. 14.

Capgemini Consulting. (2011). MIT Center for Digital Business Research, Digital Transformation: A Roadmap for Billion Dollar Organizations.

CBI. (2014). CBI product factsheet. Social Media services in Spain. CBI Ministry of Foreign Affairs.

Central Bank of Oman. (2014). Towards a Growing, Competitive and Dynamic Small and Medium-Sized Enterprises Sector in Oman: Strategy and Policies, Central Bank of Oman.

Central Intelligence Agency. (2013). The World Factbook - Oman. Retrieved from https://www.cia.gov/library/ publications/the-world-factbook/geos/mu.html

Cox, A. (2015). Outlook 15 by Core Media.

Dierdorp, S. E. (2013). A Framework for a Social Media Dashboard for Entrepreneurs. $18^{\text {th }}$ Twente Student Conference on IT, January 25th, 2013, Enschede, The Netherlands.

Doing Business. (2010). Reforming through difficult times. Co-publication of the World Bank, IFC and Palgrave MacMillan.

Doing Business. (2014). Understanding regulations for small and medium-size enterprises (11th ed.). Co-publication of The World Bank and IFC.

Dubai School of Government. (2012). Dubai School of Government's Social Media, Employment and Entrepreneurship. New Frontiers for the Economic Empowerment of Arab Youth? Produced by the Dubai School of Government's Governance and Innovation Program, in association with SAP MENA. October 2012.

Duggan, M., Ellison, N. B., Lampe, C., Lenhart, A., \& Madden, M. (2015). Social Media Update 2014. Pew Research Center, January 2015.

E-consultancy. (2011). State of Social Report 2011. Published by E-consultancy, in association with LBi and bigmouthmedia

European Commission. (2003). Green Paper on Entrepreneurship in Europe.

Facebook. (2015). Retrieved from https://newsroom.fb.com/company-info/ 
GSMA. (2014). The Mobile Economy. Arab States 2014. GSM Association. Retrieved from http://www.arabstates.gsmamobileeconomy.com

GWI. (2015). GWI Social Summary. GlobalWebIndex's quarterly report on the latest trends in social networking. Q1 2015.

Hall, N. (2013). Social Media Services Market Analysis. Sitel Key Take-Outs. CMS Program.

Instagram. (2015). Retrieved from https://www.instagram.com/about/us/

ITA. (2013). E-Participation Guidelines for Using Social Media in Government. Version 2.0. Information Technology Authority July 2013.

ITA. (2014). Survey on "Access to, and Use of, Information and Communication Technology (ICT) by Households and Individuals". Retrieved from http://www.ita.gov.om/ITAPortal/ITA/

Kaplan A. M., \& Haenlein, M. (2010). Users of the world, unite! The challenges and opportunities of Social Media. Business Horizons, 53, 59-68.

LinkedIn. (2015). Retrieved from https://www.linkedin.com/about-us

Markaz. (2014). Markaz Sector Reports 2014. GCC Social media. Revolutionizing interactions. Kuwait Financial Center K.P.S.C. (Markaz).

McKinsey \& Co. (2012). Turning Buzz into Gold. How pioneers create value from Social media. McKinsey \& Company.

Mediate. (2015). Mediate 2014-2015 (5th ed.). SABCO Press, Publishing \& Advertising LLC, Oman

Nambisan, P., \& Watt, J. H. (2011). Managing customer experiences in online product communities. Journal of Business Research, 64, 889-895.

NCSI. (2015). National Center for Statistics and Information, Oman. Retrieved from http://www.ncsi.gov.om/ NCSI_website/N_Default.aspx

OCI. (2015). Oman Collective Intelligence. Retrieved from http://www.oman-collective-intelligence.com/2015/ 01/how-to-sell-your-products-directly-on.html

Oman Economic Review. (2012). Retrieved from http://www.oeronline.com/php/2012/july/cover.php

Ozbilgin. (2009). Career Choice in Management and Entrepreneurship (p. 2). USA: Edward Elgar.

Recma. (2015). RECMA Advertiser Online Database (AOD). Retrieved from http://www.recma.com/Advertiser OnlineDatabase(AOD)Free.html?wpid=23985

Saleh, S. (2012). Business, Barriers and Benefits: E-Business for SME's in the Sultanate of Oman. International Journal of Business and Management Studies.

Salem, F., \& Mourtada, R. (2012). Social media in the Arab world: Influencing societal and cultural change? Arab Social Media Report, 2(1).

Salem, F., Mourtada, R., \& Alshaer. S. (2013). Transforming Education in the Arab World: Breaking Barriers in the Age of Social Learning', Dubai School of Government - Governance and Innovation Program. Arab Social Media Report (5th ed.).

Salem, F., Mourtada, R., \& Alshaer, S. (2014). Citizen Engagement and Public Services in the Arab World: The Potential of Social Media. Dubai School of Government - Governance and Innovation Program. Arab Social Media Report (6th ed.).

Shachmurove, Y. (2009). Entrepreneurship in Oman. Penn Institute for Economic Research, Department of Economics, University of Pennsylvania.

Shrivastava, S., \& Shrivastava, R. (2013). Role of Entrepreneurship in Economic Development - With special focus on necessity entrepreneurship and opportunity entrepreneurship. Int Journal of Management and Social Sciences Research, 2(2).

SME Advisor. (2016). Doing Business in Oman. Retrieved February 11, 2016, from http://www.smeadvisor.com/ featured/doing-business-in-oman

SMMITS. (2015). Social Media Marketing - India Trends Study. Insights from social media-savvy brands in India (2nd ed.). Ernst and Young.

Social Bakers. (2015). Retrieved from http://www.socialbakers.com 
Spitzer, B. et al. (2013). The Digital Talent Gap Developing Skills for Today's Digital Organizations. Capgemini Consulting. Retrieved from https://www.capgemini.com/resource-file-access/resource/pdf/the_digital_tale nt_gap27-09_0.pdf

Stelzner, M. A. (2014). The Social Media Marketing Industry Report. How marketers are using social media to grow their businesses. Published by Social Media Examiner: Michaela A Stelzner.

The research council. (2013), Annual report 2013. The research council (TRC).

The SoDA Report. (2014). Digital Marketing Outlook. The Soda Report. Retrieved from http://www.sodaspeaks.com

Toral, S. L., Martinez-Torres, M. R., Barrero, F., \& Cortes, F. (2009). An empirical study of the driving forces behind online communities. Internet Research, 19(4), 378-392.

Twitter. (2015). Retrieved from https://about.twitter.com/company

UNICEF Oman. (2010). Partnerships Mapping in Oman: Overview of CSR Activities. UNICEF-Oman Country Office.

We Are Social. (2014). Digital landscape: Middle East, North Africa \& Turkey. We are social's snapshot of key digital statistics and data.

WEF. (2015). The Global Competitiveness Report 2014-2015 (Ed.: Professor Klaus Schwab). World Economic Forum.

World Bank. (2015). Retrieved from http://databank.worldbank.org/data/reports.aspx?source=2\&country=OMN \&series $=\&$ period $=\#$ advanced

Y\&R. (2015). Y\&R Group Switzerland. Trends Social Media. Retrieved from http://www.yr.com/sites/vmldev. com/files/SocialMediaFyler_148x210ra_Farbig_EN.pdf

YouTube. (2015). Retrieved from https://www.youtube.com/yt/press/statistics.html

\section{Copyrights}

Copyright for this article is retained by the author(s), with first publication rights granted to the journal.

This is an open-access article distributed under the terms and conditions of the Creative Commons Attribution license (http://creativecommons.org/licenses/by/3.0/). 